\title{
PERSPECTIVE
}

\section{A new classification of ocular surface burns}

\author{
Harminder S Dua, Anthony J King, Annie Joseph
}

Ocular burns constitute true ocular emergencies and both thermal and chemical burns represent potentially blinding ocular injuries. Thermal burns result from accidents associated with firework explosions, steam, boiling water, or molten metal (commonly aluminium). Chemical burns may be caused by either alkaline or acidic agents. Common alkaline agents include ammonium hydroxide used in fertiliser production, sodium hydroxide (caustic soda) used for cleaning drains and pipes, and calcium hydroxide found in lime plaster and cement. Alkaline agents are particularly damaging as they have both hydrophilic and lipophilic properties, which allow them to rapidly penetrate cell membranes and enter the anterior chamber. Alkali damage results from interaction of the hydroxyl ions causing saponification of cell membranes and cell death along with disruption of the extracellular matrix. Common acidic agents causing injury include sulphuric acid found in car batteries, sulphurous acid found in some bleaches, and hydrochloric acid used in swimming pools. Acids tend to cause less damage than alkalis as many corneal proteins bind acid and act as a chemical buffer. In addition, coagulated tissue acts as a barrier to further penetration of acid. Acid binds to collagen and causes fibril shrinkage.

Historically, it has been recognised that the extent of tissue damage is a prognostic indicator of recovery following ocular surface injury. Recovery of ocular surface burns depends upon the causative agent and the extent of damage to corneal, limbal, and conjunctival tissues at the time of injury. Damage to intraocular structures influences the final visual outcome. Ballen ${ }^{1}$ first suggested a classification which was later modified by Roper-Hall to provide prognostic guidelines based on the corneal appearance and the extent of limbal ischaemia. ${ }^{2}$ This classification has become the commonly used benchmark since its introduction in 1965 (Table 1).

However, in the years following the introduction of the Roper-Hall classification, our knowledge and understanding of ocular surface healing and our approach to surgical management of ocular surface burns has changed dramatically. The understanding and clinical application of the concept of limbal stem cells ${ }^{3-9}$ of the corneal epithelium and forniceal stem cells of the conjunctival epithelium, ${ }^{10}{ }^{11}$ has significantly improved the outcome of treatment in patients with ocular surface burns.

Corneal epithelium is derived from limbal based epithelial stem cells; these slow cycling cells are believed to be located in the basal epithelial layer of the palisades of Vogt,

\begin{tabular}{|c|c|c|c|}
\hline Grade & Prognosis & Cornea & Conjunctiva/limbus \\
\hline I & Good & Corneal epithelial damage & No limbal ischaemia \\
\hline II & Good & Corneal haze, iris details visible & $<1 / 3$ limbal ischaemia \\
\hline III & Guarded & $\begin{array}{l}\text { Total epithelial loss, stromal } \\
\text { haze, iris details obscured }\end{array}$ & $\begin{array}{l}1 / 3-1 / 2 \text { limbal } \\
\text { ischaemia }\end{array}$ \\
\hline IV & Poor & $\begin{array}{l}\text { Cornea opaque, iris and pupil } \\
\text { obscured }\end{array}$ & $\begin{array}{l}>1 / 2 \text { limbal } \\
\text { ischaemia }\end{array}$ \\
\hline
\end{tabular}

at the limbus. ${ }^{12} 13$ They are poorly differentiated and are thought to maintain their "stemness" through a combination of inherent cellular characteristics and the presence of a favourable microenvironment at the limbus. ${ }^{9}$ These stem cells provide a steady supply of daughter cells (transient amplifying cells) which maintain a constant epithelial cell mass during normal epithelial cell turnover and during epithelial wound healing. Corneal epithelial regeneration occurs in both a centripetal and circumferential manner with cells growing from the limbus towards the central cornea and also migrating along the limbus. ${ }^{10}{ }^{14}$ The stem cells of the conjunctiva are located in the forniceal region and migrate in a centripetal fashion away from the fornices to cover bulbar and tarsal conjunctiva. ${ }^{10}{ }^{11}$

New developments in the management of ocular surface burns, such as autolimbal ${ }^{15}$ or allolimbal transplantation $^{17-19}$ with or without amniotic membrane transplantation, ${ }^{20-23}$ combined with systemic immunosuppression and topical instillation of autologous serum, have all evolved from the better understanding of ocular surface regeneration and healing from limbal and forniceal stem cells. Ocular surface reconstruction procedures are being carried out with increasing frequency worldwide. However, the successes and failures reported for these procedures vary from centre to centre even for the same grade of burns. ${ }^{22-26}$ This difference is largely a reflection on the inadequacy of the present classification system, rather than on the use of amniotic membrane or limbal transplantation. This is particularly true for grade IV burns. In the Roper-Hall ${ }^{2}$ classification grade IV implies between $50 \%-100 \%$ limbal ischaemia and is equated with a poor prognosis. However, with present management strategies, an eye with $50 \%$ or even $75 \%$ limbal ischaemia can expect a good to fair outcome, whereas an eye with $100 \%$ ischaemia is very likely to have a poor outcome. The extent of associated conjunctival epithelial involvement is another variable of considerable prognostic significance. In eyes with total loss of limbal (and corneal) epithelium, the presence of any surviving conjunctival epithelium, is a favourable prognostic indicator when compared with eyes with total loss of corneal, limbal, and conjunctival epithelium. Conjunctival epithelial cover to the cornea (and ocular surface) is better than no epithelial cover. Conjunctivalisation of the cornea protects against progressive melting and perforation. The ensuing vascularisation promotes healing and facilitates repair. This allows the eye to settle and provides an opportunity to carry out restorative procedures at a future date. In eyes with $100 \%$ limbal and conjunctival involvement, a very poor outcome would be expected even with maximum intervention.

There are several examples of good outcomes in RoperHall grade IV burns following using modern management approaches described above. Morgan and Murray ${ }^{27}$ treated six cases of grade IV burns with autolimbal transplantation and reported success in five eyes. Kenyon and Tseng ${ }^{15}$ reported use of autolimbal transplantation in 22 cases of 


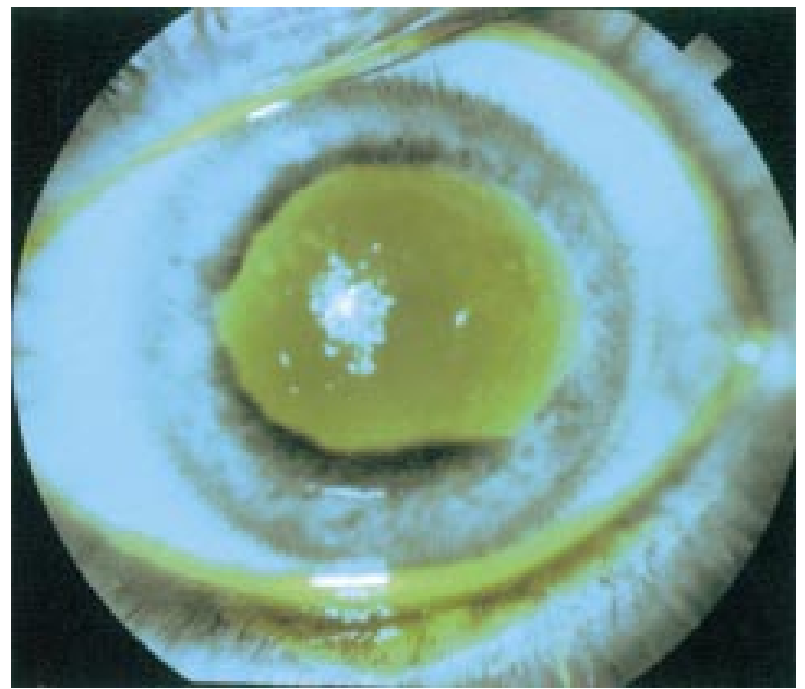

Figure 1 Grade 1 ocular surface burn. Large corneal burn following accidental exposure to ammonia. There is no limbal or conjunctival involvement. Fluorescein stained diffuse view of the cornea.

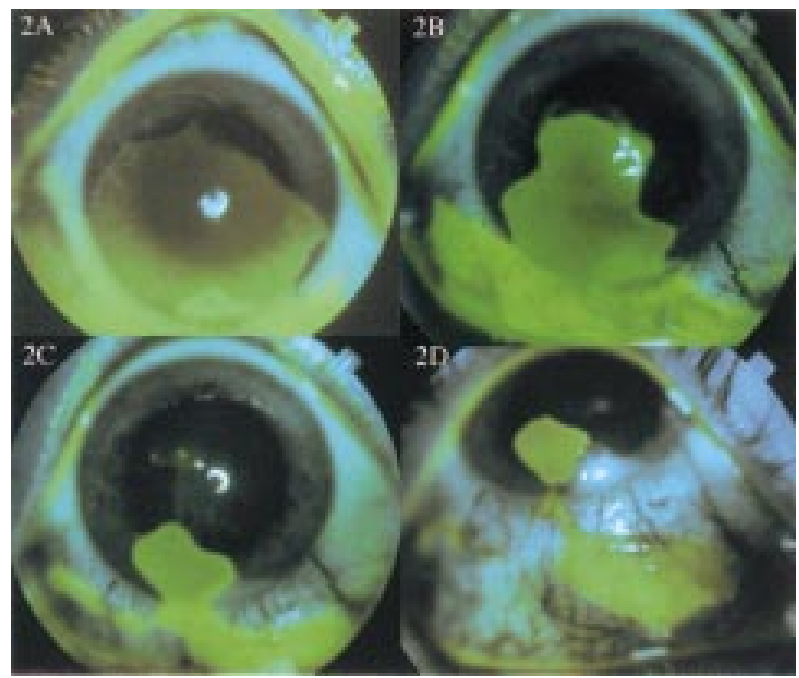

Figure 2 (A) Grade 3 (4.5/30\%) ocular surface burn. Four and a half clock hours of limbus involvement with $30 \%$ conjunctival involvement following ocular surface burn with a domestic cleansing (alkali) injury.

$(B)$ and $(C)$ the surviving limbal epithelium demonstrates circumferential migration of tongue-shaped projections affording limbal epithelial cover to denuded limbus. (D) The entire limbus has healed with limbal epithelium and the corneal surface too is almost completely healed with corneal (imbal derived) epithelium. The conjunctival defect is closing with conjunctival epithelium. Fluorescein stained diffuse view of the cornea.

ocular surface burns with considerable success. Although they did not use a classification system to grade the severity of burns, from their description and illustrations of the patients it is clear that several of them would be in the grade IV category of the Roper-Hall classification. Tsai et $a l^{28}$ used ex vivo expanded limbal epithelium of amniotic sheets to restore the ocular surface in three patients with chemical burns, of which at least two were grade IV with total limbal deficiency. Other examples of similar success are reported in the literature. ${ }^{2324}{ }^{29}$ However, not all cases in the reported series have had a good outcome. The extent of limbal involvement within grade IV is not always clear in these reports.

Pfister $^{30}$ attempted to "simplify the classification" by presenting a group of drawings to grade severity of involvement into normal, mild, moderate, moderate to severe, severe, and very severe. Brodovsky et $a l^{\beta 1}$ undertook an 11 year retrospective review of 177 eyes with alkali burns and commented that "The classification of injury severity, in

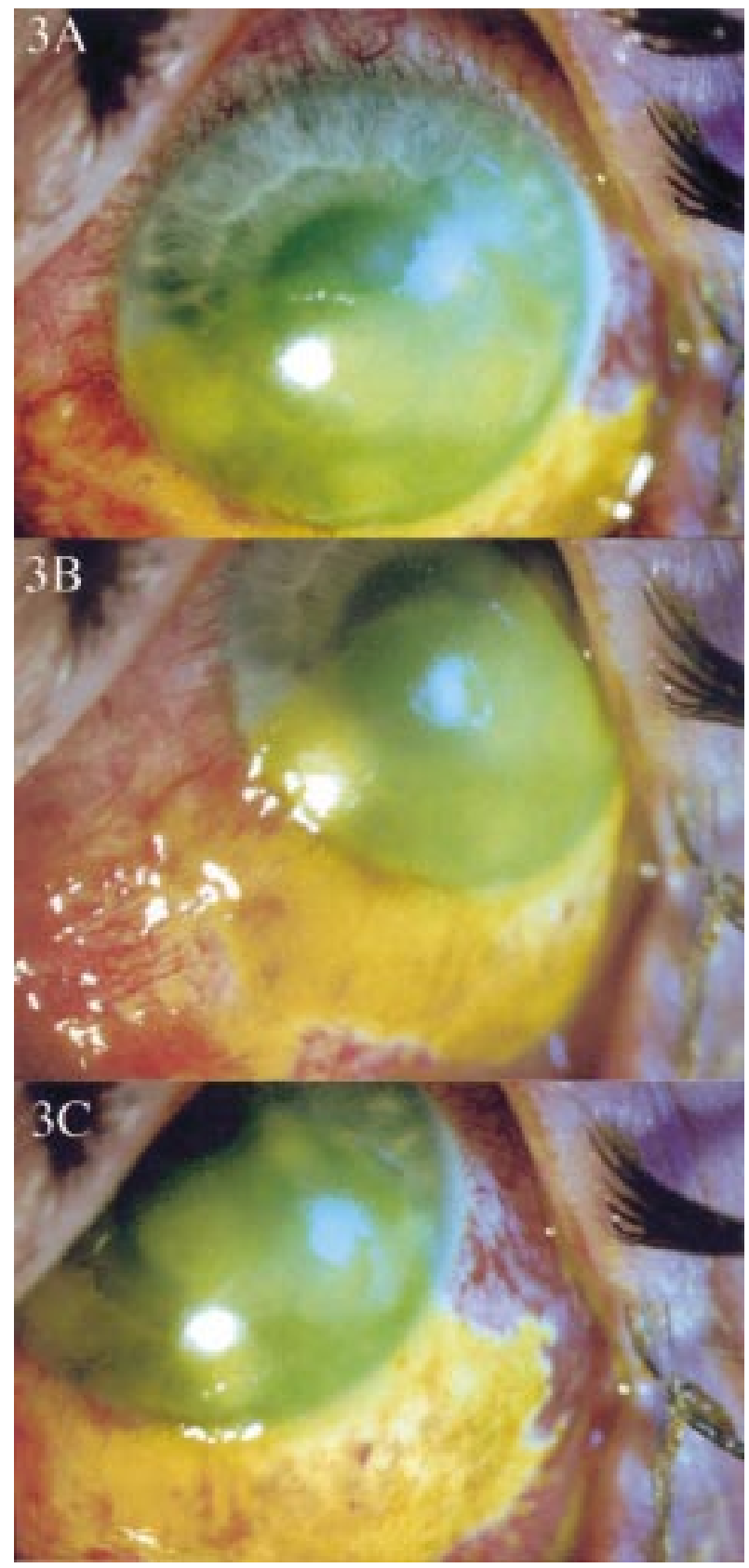

Figure 3 Grade 3 (5/35\%) ocular surface burn following an accident involving an industrial alkaline chemical. Five clock hours of the limbus and $35 \%$ of the conjunctiva were involved. (A) Diffuse view with patient looking straight illustrating the extent of limbal involvement. (B) Diffuse view with patient looking up and out and $(C)$ looking up and in to show the extent of conjunctival involvement. (With the Roper Hall grading (III) this would carry a guarded prognosis. This patient made a complete recovery.)

particular the clinical assessment of limbal ischaemia, is imprecise and varies among different clinicians."

The Roper-Hall classification is thus proving inadequate in planning interventional strategies and predicting outcome in such cases. It also appears to be contributing to some of the inconsistencies in success rates reported in the literature. ${ }^{24-26}$

\section{New classification for ocular surface burns}

We propose a significant modification to the Roper-Hall classification to take into account the extent of limbal involvement in clock hours, and the percentage of conjunctival involvement. Clock hours of the limbus was 


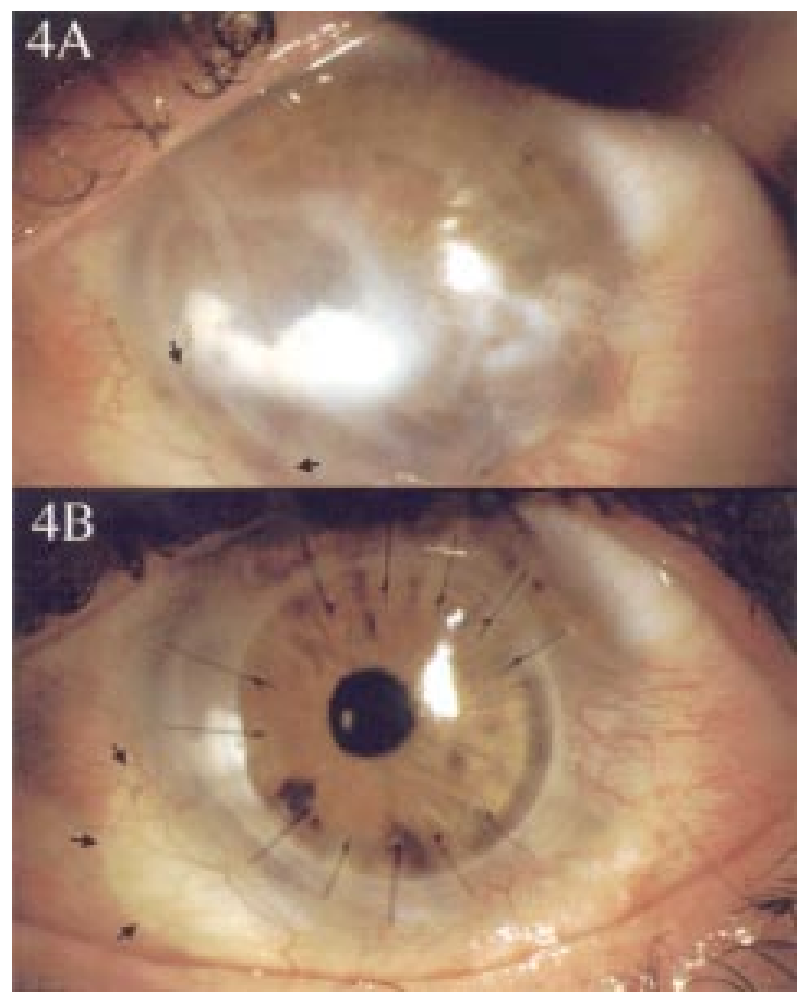

Figure 4 Grade 4 (7/50\%) ocular surface burn following an acid burn. Seven clock hours of the limbus and 50\% of the conjunctiva were involved. (A) An autolimbal transplant was first carried out in the inferior nasal quadrant (arrows). (B) One year after a full thickness corneal transplant that succeeded the autolimbal transplant by 4 months. Arrows show the limits of the autologous conjunctiva attached to the peripheral corneal strip that constituted the "autolimbal graft." The patient has been followed for 2.5 years and retains a clear graft. (With the Roper Hall grading (IV) this would carry a poor prognosis.)

determined by dividing the limbus into 12 hours of a clock face. The term "limbal involvement" is preferred over "limbal ischaemia" because it is broader in its connotation and will not exclude areas of limbus where a complete or full thickness loss of limbal epithelium has occurred without significant ischaemia. Total loss of limbal epithelium (including the stem cells) can occur despite little ischaemia but has potentially the same consequences.

Although limbal ischaemia is usually associated with loss of limbal stem cells, this is not always the case. Transient ischaemia, or ischaemia occurring soon after the injury but recovering in the ensuing days, may allow limbal stem cells to survive, recover or repopulate the affected sector. Similarly, superficial "limbal involvement" can result in $360^{\circ}$ of surface staining with deeper stem cells surviving. This situation may not become apparent until a few days after the injury. Because it is clinically not possible to evaluate this situation at the time of injury, it is proposed that the extent of limbal involvement at the time of injury, be based on the clock hours of limbal staining observed. The extent of involvement should then be reviewed frequently (daily or every other day as appropriate), and the classification changed in the follow up period to reflect the continuum of change that occurs in the immediate post injury period. Conversely, in some instances a sector of limbus that appears to have survived the initial insult sloughs off in the post injury period. This would make the classification or grade more severe than was originally thought and such occurrences need to be taken into account. The proposed classification is flexible enough to enable accurate documentation of these changes, unlike the current classification which does not allow for such changes to be taken

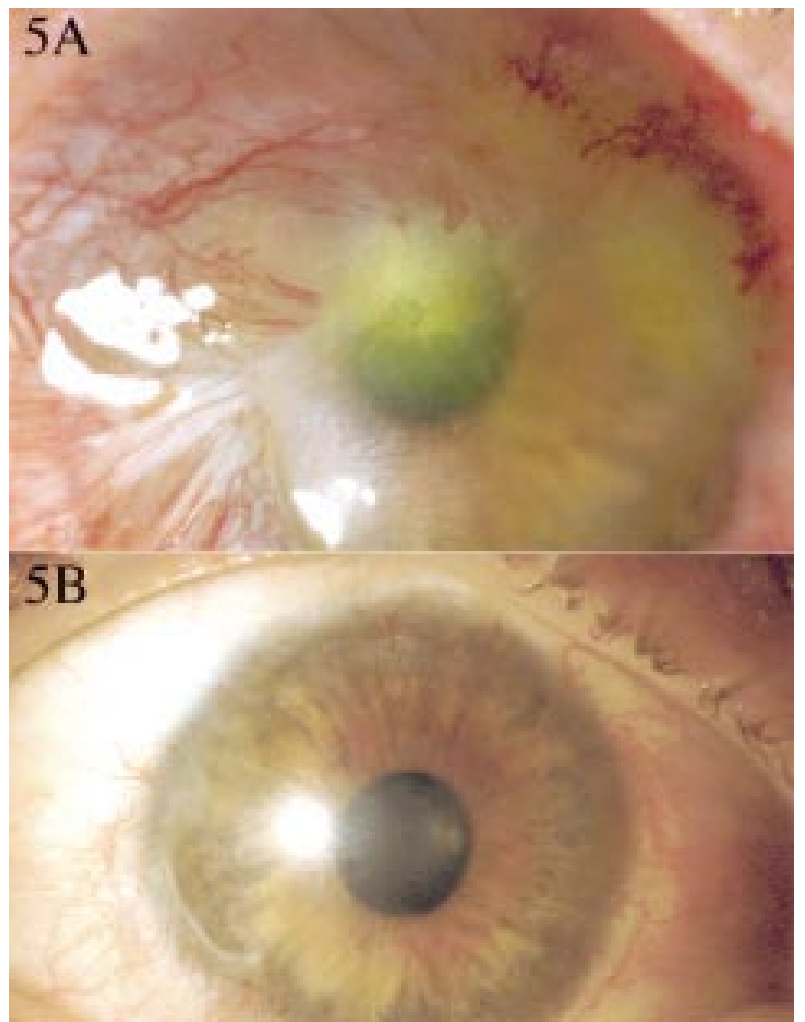

Figure 5 Grade 5 (9.5/60\%) ocular surface burn following alkali injury. Nine and a half clock hours of the limbus and $60 \%$ of the conjunctiva were involved. (A) Diffuse view of the cornea showing extensive conjunctivalisation and a fibrovascular pannus. (B) The eye 13 months after ocular surface reconstruction with autolimbal transplantation. (With the Roper Hall grading (IV) this would carry a poor prognosis.)

into account in determining the clinical extent of injury and its implications for subsequent outcome.

Conjunctival involvement was estimated by dividing the bulbar and forniceal conjunctiva into quadrants and determining the area involved. It is rare for the entire conjunctiva (bulbar, forniceal, tarsal) to be involved in ocular surface burns but does occur, especially after molten aluminium burns and caustic soda (drain cleaner) burns. However, for the purpose of the classification, only bulbar conjunctival involvement up to and including the fornices is considered significant in the context of the eventual outcome. In other words, if the entire bulbar and forniceal conjunctiva is involved, it becomes immaterial if some proportion of the tarsal conjunctiva survives. In our experience, we have not noted this to influence the eventual outcome in any demonstrable manner.

This classification (see Table 2) is based on our experience of 67 cases of ocular surface burns (of all grades) managed over several years (35 retrospective and 32 prospective).

The best outcome is to be expected when a "burn injury" produces a corneal epithelial defect without any limbal or conjunctival involvement. This is the commonest type of corneal epithelial damage seen following minor accidents involving household soap solutions or alcohol based cleaning agents. This would be classified as grade 1 (Fig 1). When less than 3 clock hours of the limbus are involved and less than $30 \%$ of the adjoining or adjacent conjunctiva is also involved, a good prognosis can be expected with conventional medical management. This includes measures such as copious irrigation soon after injury, use of topical vitamin C drops, citrate drops, acetylcysteine drops, judicious use of steroids, and prophylactic antibiotics. Such an injury would be classified as grade 2 . 


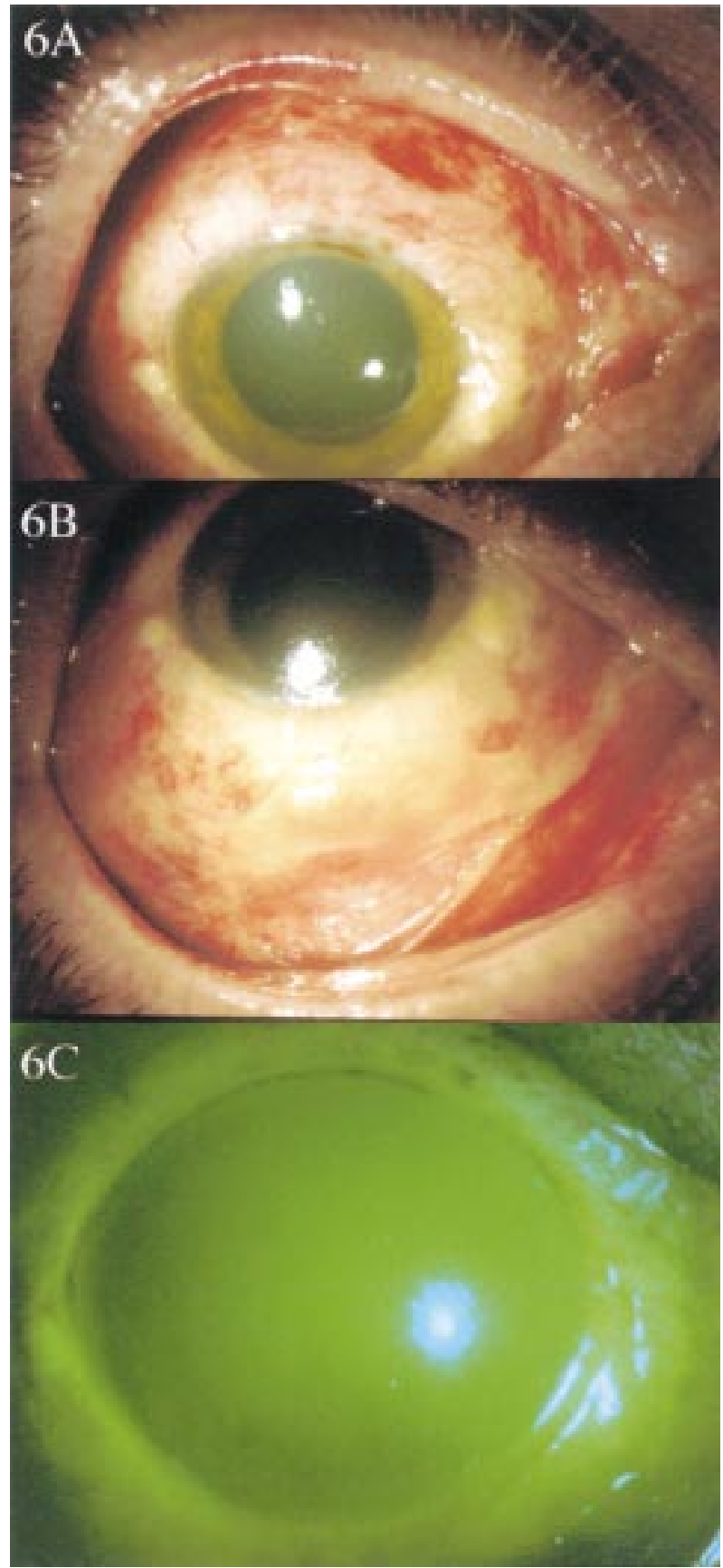

Figure 6 Grade 6 (12/100\%) ocular surface burn with a "fish pond cleaning liquid" following an assault. The entire limbus and the entire conjunctiva were involved. (A) Diffuse view showing involvement of the entire upper and (B) lower bulbar conjunctiva. (C) The entire corneal surface and 12 clock hours of the limbus are involved. This patient carries a very poor prognosis.

Grades 1 and 2 closely parallel the Roper-Hall classification with the additional inclusion of conjunctival involvement in the equation. A good outcome can also be expected when limbal involvement is between 3 and 6 clock hours associated with conjunctival involvement of between $30 \%$ and $50 \%$. This would represent a grade 3 injury (Figs 2 and 3). Besides conventional medical management as mentioned above, it is important to monitor these patients closely with regard to conjunctival epithelial migration on to the corneal surface as described before. ${ }^{32}$ Although it carries a similar prognosis to a grade 2 injury, it is classified as a higher grade to reflect the increased severity of the injury and the closer observation

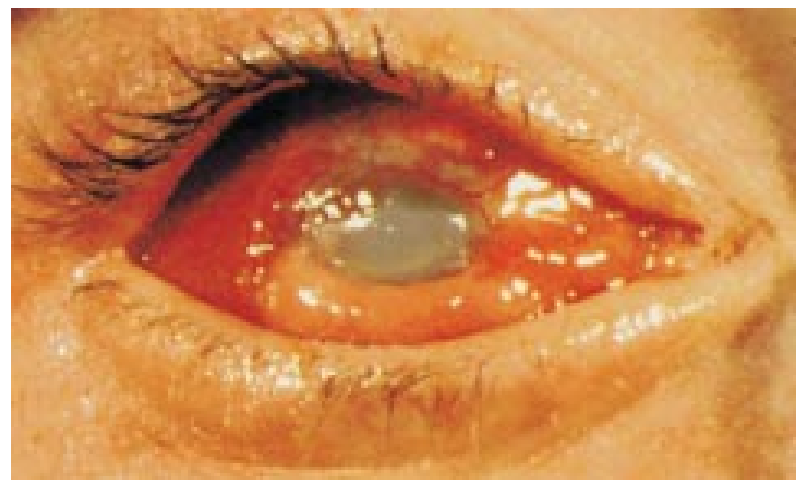

Figure 7 Grade $6(12 / 100 \%)$ ocular surface burn following injury with cement powder. The entire limbus and conjunctiva were involved. This picture was taken 7 months after the injury. The eye is becoming pthysical with extensive symblepharon. This illustrates the very poor prognosis of a grade 6 burn. (With the Roper Hall grading Figs 4, 5, 6, and 7 would all be grouped under grade IV with a poor prognosis.)

and extended nature of the management required to induce a favourable outcome.

When limbal involvement is between 6 and 9 clock hours and the conjunctival involvement is between $50 \%$ and $75 \%$ the prognosis is guarded but reconstruction of the ocular surface with a good outcome is possible (Fig 4). This would be classified as grade 4 under the proposed new classification. Limbal involvement of greater than 9 clock hours but less than 12 clock hours (Fig 5) indicates quite a severe injury (grade 5) but not as bad as an injury where the entire limbus $(100 \%)$ and entire conjunctiva $(100 \%)$ (Fig 6) are involved (grade 6) (see Table 2). As long as there is even 1 clock hour of limbal epithelium surviving, there is an opportunity to re-establish corneal epithelial cover over, if not the entire cornea, at least the visual axis. Under the Roper-Hall classification, grades 4, 5, and 6 would be included under grade 4 with a poor prognosis. This is clearly not the case when one considers the management options available to us today (Figs 4 and 5). Of particular importance are procedures including amniotic membrane transplantation, ${ }^{20-23}$ autolimbal transplantation, ${ }^{1516}$ and allolimbal transplantation. ${ }^{17-19}$ Even with these techniques, however, the prognosis of grade 6 burns (12 clock hours of limbus and 100\% conjunctival involvement) is still poor (Fig 7).

It is also very important to emphasise the significance of (any) surviving conjunctival epithelium following "burn injuries." Although it is ideal and desirable to re-establish corneal epithelial cover for the cornea, in the higher grades of burns, particularly grades 4 and 5, this may not always be possible. In this situation, any form of epithelial cover to the cornea is preferable to no cover at all, and the sooner it can be established the better. Conjunctivalisation of the cornea helps prevent stromal thinning and melting and allows the ocular surface epithelium to settle and quieten. This paves the way for restorative and reconstructive intervention at a later date, with a much higher chance of success than if the intervention were to be undertaken in the acute phase after injury. In a grade 6 burn, where there is no surviving conjunctival epithelium, one is forced into performing a limbal transplant (usually allografts) in the acute/active stage after injury, with a poor prognosis. Even amniotic membrane grafts, which work largely by providing a substrate for epithelial cells to grow on, fail when there are no epithelial cells, conjunctival or limbal, surviving. When attributing a grade to a given clinical situation, the extent of limbal involvement takes precedence over the extent of conjunctival involvement. When the extent of conjunctival involvement is more or less than what is ascribed to a given grade (Table 2), the grade attributed 
Table 2 New classification of ocular surface burns

\begin{tabular}{|c|c|c|c|c|}
\hline Grade & Prognosis & Clinical findings & Conjunctival involvement & Analogue scale \\
\hline I & Very good & 0 clock hours of limbal involvement & $0 \%$ & $0 / 0 \%$ \\
\hline II & Good & $\leqslant 3$ clock hours of limbal involvement & $\leqslant 30 \%$ & $0.1-3 / 1-29.9 \%$ \\
\hline III & Good & $>3-6$ clock hours of limbal involvement & $>30-50 \%$ & $3.1-6 / 31-50 \%$ \\
\hline IV & Good to guarded & $>6-9$ clock hours of limbal involvement & $>50-75 \%$ & $6.1-9 / 51-75 \%$ \\
\hline $\mathrm{V}$ & Guarded to poor & $>9-<12$ clock hours of limbal involvement & $>75-<100 \%$ & $9.1-11.9 / 75.1-99.9 \%$ \\
\hline VI & Very poor & Total limbus (12 clock hours) involved & Total conjunctiva $(100 \%)$ involved & $12 / 100 \%$ \\
\hline
\end{tabular}

*The analogue scale records accurately the limbal involvement in clock hours of affected limbus/percentage of conjunctival involvement. While calculating percentage of conjunctival involvement, only involvement of bulbar conjunctiva, up to and including the conjunctival fornices is considered.

should be that of the limbus involvement (but see analogue scale below).

This classification has the added advantage that it can be presented in an analogue manner rather in the stepped progression of a graded classification. For example, 1.5/25 would indicate $1 \frac{1 / 2}{2}$ clock hours of limbal involvement and $25 \%$ of conjunctival involvement. This flexibility would allow crossover between "grades" especially with regard to conjunctival involvement, as can be seen in real clinical situations-for example, 3/55 would represent 3 clock hours of limbal involvement and $55 \%$ of conjunctival involvement.

We recommend that the new classification system be used to score the ocular surface involvement in the analogue manner rather than in grades. The scores can be recorded on a daily basis following acute burns and can more accurately reflect progress and healing after injury. The clinical status and grade of ocular surface burn, in a given patient, can be reclassified as the condition improves or deteriorates and moves down or up the scale.

It must be pointed out that other factors also influence visual recovery and eventual outcome. The Roper-Hall classification emphasises corneal haze as an important prognostic variable. Rapid changes in corneal transparency are known to occur in the days immediately following acute chemical injury. Moreover, the ability of the denuded cornea to support regenerating epithelium, be it limbus derived or conjunctival, is the important consideration. When the corneal stromal surface is rendered unsuitable for any epithelium, as is more often seen in grades 3-6, amniotic membrane transplantation (substrate transplantation) is required and helps to encourage reepithelialisation of the cornea. Associated lid burns can cause lid shortening, rigidity, and contractures resulting in exposure keratitis and mechanical injury to the cornea, and are usually associated with poor prognosis. Intraocular pressure is another important factor. High intraocular pressure should be aggressively managed but persistent hypotony is generally an indicator of poor prognosis. Unilateral burns may tend to have a better eventual outcome, all else being equal, because of suitable tissue available from the contralateral eye for restorative work. There is no risk of graft rejection or need for systemic immunosuppression.

While remaining as simple and easy to use as the original classification, the new system will improve our ability to define with greater precision, the extent of ocular surface injury, plan management strategies, predict the outcomes of injury, and allow more uniform comparisons between published outcomes of ocular surface injury management.

H S Dua is the Julia Duane scholar (Philadelphia); A J King was the Vision Express cornea fellow, University Hospital, Nottingham; Annie Joseph is a research fellow, University Hospital, Nottingham.
HARMINDER S DUA ANTHONY J KING ANNIE JOSEPH

Division of Ophthalmology and Visual Sciences, B floor, Eye, Ear Nose and Throat Centre, University Hospital, Queen's Medical Centre, Nottingham NG7 2UH, UK

1 Ballen PH. Treatment of chemical burns of the eye. Eye, Ear, Nose and Throat Monthly 1964;43:57-8.

2 Roper-Hall MJ. Thermal and chemical burns. Trans Ophthalmol Soc UK 1965;85:631-53.

3 Kinoshita S, Kiorpes TC, Friend J, et al. Limbal epithelium in ocular surface wound healing. Invest Ophthalmol Vis Sci 1982;23:73-80.

4 Chen JJ, Tseng SC. Corneal epithelial wound healing in partial limbal deficiency. Invest Ophthalmol Vis Sci 1990;31:1301-14.

5 Chen JJ, Tseng SC. Abnormal corneal epithelial wound healing in partial-thickness removal of limbal epithelium. Invest Ophthalmol Vis Sci 1991;32:2219-33.

6 Kruse FE. Stem cells and corneal epithelial regeneration. Eye 1994;8:17083.

7 Huang AJ, Tseng SC. Corneal epithelial wound healing in the absence of limbal epithelium. Invest Ophthalmol Vis Sci 1991;32:96-105.

8 Dua HS. Stem cells of the ocular surface: scientific principles and clinical applications. Br f Ophthalmol 1995;79:968-9.

9 Dua HS, Azuara-Blanco A. Limbal stem cells of the corneal epithelium. Surv Ophthalmol 2000;44:415-25.

Surv Ophthalmol 2000;44:415-25.
10 Dua HS, Forrester JV. The corneoscleral limbus in human corneal epithelial wound healing. Am $\mathcal{f}$ Ophthalmol 1990;110:646-56.

11 Wei ZG, Wu RL, Lavker RM, et al. In vitro growth and differentiation of rabbit bulbar, fornix, and palpebral conjunctival epithelia. Implications on conjunctival epithelial transdifferentiation and stem cells. Invest Ophthalmol Vis Sci 1993;34:1814-28.

12 Davanger M, Evensen A. Role of the pericorneal papillary structure in renewal of corneal epithelium. Nature 1971;229:560-61.

13 Townsend WM.The limbal palisades of Vogt. Trans Am Ophthalmol Soc 1991;89:721-56.

14 Dua HS, Forrester JV. Clinical patterns of corneal epithelial wound healing. Am F Ophthalmol 1987;104:481-9.

15 Kenyon KR, Tseng SC. Limbal autograft transplantation for ocular surface disorders. Ophthalmology 1989;96:709-23.

16 Dua HS, Azuara-Blanco A. Autologous limbal transplantation in patients with unilateral corneal stem cell deficiency. Br F Ophthalmol 2000;84:273-8.

17 Tsubota K, Toda I, Saito H, et al. Reconstruction of the corneal epithelium by limbal allograft transplantation for severe ocular surface disorder. Ophthalmology 1995;102:1486-96.

18 Tsai RJ, Tseng SC. Human allograft limbal transplantation for corneal surface reconstruction. Cornea 1994;13:389-400.

19 Dua HS, Azuara-Blanco A. Allo-limbal transplantation in patients with limbal stem cell deficiency. Br f Ophthalmol 1999;83:414-19.

20 Tseng SC, Prabhasawat P, Lee SH. Amniotic membrane transplantation for conjunctival surface reconstruction. Am f Ophthalmol 1997;124:765-74.

21 Tseng SC, Prabhasawat P, Barton K, et al. Amniotic membrane transplantation with or without limbal allografts for corneal surface reconstruction in patients with limbal stem cell deficiency. Arch Ophthalmol 1998;116:431-41.

22 Azuara-Blanco A, Pillai CT, Dua HS. Amniotic membrane transplantation for ocular surface reconstruction. Br F Ophthalmol 1999;83:399-402.

23 Shimazaki J, Yang HY, Tsubota K. Amniotic membrane transplantation for ocular surface reconstruction in patients with chemical and thermal burns. Ophthalmology 1997;104:2068-76.

24 Meller D, Pires RT, Mack RJ, et al. Amniotic membrane transplantation for acute chemical or thermal burns. Ophthalmology 2000;107:980-9.

25 Dua HS, Azuara-Blanco A. Discussion on amniotic membrane transplantation for acute chemical or thermal burns. Ophthalmology 2000;107:990.

26 Joseph A, Dua HS, King AJ. Failure of amniotic membrane grafting in acute Joseph A, Dua HS, King AJ. Failure of amniotic me
chemical burns. Br $\mathcal{F}$ Ophthalmol 2001;(in press).

27 Morgan S, Murray A. Limbal autotransplantation in the acute and chronic phases of severe chemical injuries. Eye 1996;10:349-54.

28 Tsai RJ, Li L, Chen J. Reconstruction of damaged corneas by transplantation of autologous limbal epithelial cells. $N$ Engl $\mathcal{F}$ Med 2000;343:86-93.

29 Sridhar MS, Bansal AK, Sangwan VS, et al. Amniotic membrane transplantation in acute chemical and thermal injury. Am F Ophthalmol 2000;130: 134-7.

30 Pfister RR. Chemical injuries of the eye. Ophthalmology 1983;90:1246-53.

31 Brodovsky SC, McCarty CA, Snibson G, et al. Management of alkali burns. An 11 year retrospective review. Ophthalmology 2000;107:1829-35.

32 Dua HS. The conjunctiva in corneal epithelial wound healing. Br f Ophthalmol 1998;82:1407-11. 